\title{
CARA PEMBUATAN E-BOOK (Electronic Book) DENGAN MEMANFAATKAN FITUR SIGIL Ver 0.9.4 FORMAT EPUB
}

\author{
Ahmad Indra Harahap ${ }^{1}$ \\ ${ }^{1}$ Program Studi Sistem Informasi, STMIK Citra Mandiri Padangsidimpuan \\ ${ }^{1}$ artificialintelegent008@gmail.com
}

\begin{abstract}
The times in the all-technological era now have many changes including changes in reading books. People read in the form of physical books and there are also those who read books in the form of digital e-books (Electronic Book) on computers, laptops or smartphones. Epub (electronic publication) is a digital book format, which is a standardized form, introduced by the International Digital Publishing Forum (IDPF) in October 2011. Epub replaces the role of Open eBook as an open book format. Epub consists of multimedia files, html5, css, xhtml, $x \mathrm{ml}$ which are made into one file with the epub extension.

Epub is one of the most popular digital book formats today, as a format that does not refer to any particular developer, Epub has several advantages over other digital book formats, Epub has the dynamic characteristic of adapting to the screen size of a laptop device, computers or smartphones and has other advantage features.

Sigil is an open-source editor for EPUB developed by Strahinja Markovic in 2009 and maintained by John Schember since 2011. As a cross-platform application, it is distributed for Microsoft Windows, Mac OS X and Linux platforms under the GNU GPL license. Sigil supports WYSIWYG and code editing based on EPUB files, as well as import of HTML and plain text files. SIGIL is an editor application for creating digital books in Epub format which are Open Source

Researchers used literature studies as a research reference by collecting documents from several library sources needed in the study. This is done to obtain the information and data needed for this study using a sigil editor application for making digital books in the epub format. From this research, the researcher digs up knowledge so that this knowledge can be realized at STMIK Citra Mandiri Padangsidimpuan. Therefore, the author will examine "HOW TO MAKE E-BOOK (Electronic Book) USING SIGIL FEATURES" which later this research will be made in a journal. Hopefully it can be useful for the author himself and for readers. Hopefully this research can produce useful knowledge for researchers and STMIK Citra Mandiri Padangsidimpuan and also the reading public.
\end{abstract}

Keywords: digital book, sigil, epub, e-book

Abstrak

Perkembangan zaman di era serba teknologi sekarang banyak perubahan termasuk juga perubahan dalam membaca buku. Orang membaca dalam bentuk buku fisik dan juga ada yang membaca buku dalam bentuk digital e-book (Electronic Book) di komputer, laptop maupun di smartphone. Epub (electronic publication) merupakan salah satu format digital book yang merupakan format standardisasi bentuk, diperkenalkan oleh International Digital Publishing Forum(IDPF) pada Bulan Oktober Tahun 2011. Epub menggantikan peran Open eBook sebagai format buku terbuka. Epub terdiri atas file multimedia, html5, css, xhtml, xml yang dijadikan satu file dengan ekstensi .epub.

Epub merupakan salah satu format buku digital yang paling populer saat ini, sebagai format yang tidak mengacu kepada salah satu pengembang tertentu, Epub mempunyai beberapa kelebihan fitur dibandingkan format buku digital yang lain, Epub memiliki karakteristik yang dinamis dapat menyesuaikan diri dengan ukuran layar perangkat laptop, komputer maupun smartphone dan memiliki fitur kelebihan lainnya.

Sigil adalah editor open-source untuk EPUB yang dikembangkan oleh Strahinja Markovic pada tahun 2009 dan dikelola oleh John Schember sejak tahun 2011. Sebagai aplikasi cross-platform, itu didistribusikan untuk Microsoft Windows, Mac OS X dan platform Linux di bawah lisensi GNU GPL. Sigil mendukung WYSIWYG dan mengedit kode berbasis file EPUB, serta impor HTML dan file teks biasa. SIGIL merupakan aplikasi editor untuk membuat buku digital berformat Epub yang bersifat Open Source

Peneliti menggunakan studi literatur sebagai referensi penelitian yaitu dengan mengumpulkan dokumen dari beberapa sumber pustaka yang diperlukan dalam penelitian. Hal ini dilakukan untuk memperoleh informasi dan data yang diperlukan untuk penelitian ini menggunakan aplikasi editor sigil untuk pembuatan buku digital berformat epub. Dari penelitian tersebut peneliti menggali ilmu agar ilmu tersebut dapat direalisasikan ke STMIK Citra Mandiri Padangsidimpuan. Oleh karna itu penulis akan meneliti "CARA PEMBUATAN E-BOOK (Electronic Book) DENGAN MEMANFAATKAN FITUR SIGIL” yang dimana nanti-nya penelitian ini akan di buat Jurnal semoga dapat bermanfaat bagi penulis sendiri maupun untuk pembaca . Semoga dari penelitian ini dapat menghasilkan ilmu yang bermanfaat untuk peneliti maupun STMIK Citra Mandiri Padangsidimpuan dan juga masyarakat yang membaca. 
Volume 10 No. 3 | Desember 2020: 228-234

Kata-kata kunci: buku digital, sigil, epub, e-book 


\section{Pendahuluan}

Perkembangan teknologi di zaman sekarang ini telah banyak perubahan dan perkemabangan termasuk juga dalam membaca buku di komputer, laptop maupun Smartphone. Di zaman sekarang ini masih banyak penjualan buku fisik maupun buku digital e-book (Electronic Book). Buku fisik jika disimpan waktu yang lama dapat mengalami degradasi kualitas kertas sehingga terjadi pelapukan kertas yang mengakibatkan buku rusak bahkan bisa habis dimakan rayap. Jika buku tersebut rusak, maka catatan buku yang memiliki ilmu pengetahuan, sejarah,seni, dan sebagainya akan hilang dimakan masa.

Di masa teknologi sekarang yang berkembang pesat minat pembaca e-book secara signifikan berkembang dan banyak diminati disebabkan banyak pengguna laptop, komputer dan juga smartphone. Smartphone dari tahun ke tahun mengalami penjualan yang tinggi sehingga banyak pernerbit maupun penulis buku berlomba membuat buku digital e-book (Electronic Book) karna mempunyai kelebihan dapat di kombinasikan dengan suara, video mau pun gambar daripada buku biasa yang hanya dapat dibaca dengan teks dan gambar saja.

E-book adalah sebuah versi elektronik dari sebuah buku tercetak yang dapat dibaca pada sebuah personal komputer atau alat lain yang didesain khusus untuk membaca e-book (Danang-2009) . Sementara Putu Laxman Pendit (2008) berpendapat buku elektonik adalah buku cetak yang diubah bentuk menjadi elektronik untuk dibaca di layar monitor. Dari beberapa pendapat ahli penulis memberi kesimpulan bahwa buku digital e-book (elektronik book) adalah buku yang dapat di baca di perangkat elektronik smartphone, komputer maupun laptop yang dapat didesain lebih menarik dengan menambahkan gambar , audio, video agar lebih mudah dipahami oleh pembaca. Untuk membuat e-book dengan tampilan yang lebih menarik dibutuhkan aplikasi editor untuk memanajemen e-book, penulis menggunakan aplikasi editor Sigil.

Sigil merupakan aplikasi untuk manajemen dan pembuatan e-book berformat epub yang bersifat open source dikembangkan oleh Strahinja Markovic pada tahun 2009 dan dikelola oleh John Schember sejak tahun 2011. Sebagai aplikasi cross-platform, itu didistribusikan untuk Microsoft Windows, Mac OS X dan platform Linux di bawah lisensi GNU GPL Peneliti nantinya akan mengumpulkan berbagai referensi dari berbagai sumber untuk pembuatan ebook. Dari penelitian tersebut peneliti menggali ilmu agar ilmu tersebut dapat direalisasikan ke STMIK Citra
Mandiri Padangsidimpuan. Oleh karna itu penulis akan meneliti "CARA PEMBUATAN E-BOOK (Electronic Book) DENGAN MEMANFAATKAN FITUR SIGIL Ver.0.9.4", yang dimana nanti-nya penelitian ini akan di buat makalah semoga dapat bermanfaat bagi penulis sendiri maupun untuk pembaca.

Berdasarkan latar belakang, maka perumusan yang akan dibuat dalam penelitian ini adalah bagaimana cara membuat buku digital e-book (Electronic Book) menggunakan fitur Sigil dengan format Epub, dengan batasan penelitian sebagai berikut :

- Menggunakan Studi Literatur untuk mengumpulkan dokumen dar berbagai sumber sebagai referensi.

- Aplikasi editor Menggunakan Sigil Ver. 0.9.4

- Buku Digital berformat epub

- Buku yang akan di edit menggunakan format html

- Bahan materi buku digital dari peneliti

Tujuan penelitan untuk membuat buku digital ebook (electronik book) dengan menggunakan fitur sigil . Manfaat penelitian ini adalah memberikan ilmu pengetahuan bagaiamana cara pembuatan e-book menggunakan fitur sigil bagi penulis sendiri dan juga STMIK Citra Mandriri Padangsidimpuan pada Program Studi Sistem Informasi serta pembaca penelitian ini, sehingga dari hasil penelitian ini nanti dapat di realisasikan di kehidupan masyarakat.

Targer luaran penelitian ini adalah sebagai berikut, dijelaskan dalam tabel 1 :

Tabel 1. Rencana Target Pencapaian

\begin{tabular}{lll}
\hline No & Jenis Luaran & $\begin{array}{l}\text { Indikator } \\
\text { Pencapaian }\end{array}$ \\
\hline 1. & Publikasi Ilmiah Jurnal Ber ISSN & Submitted \\
\hline 2. & $\begin{array}{l}\text { Pemakalah dalam } \\
\text { temu Ilmiah }\end{array}$ & Internasional \\
\cline { 3 - 4 } & Nasional & Terdaftar \\
\hline 3. & Bahan Ajar & Draft \\
\hline 4. & Artikel & Terbit \\
\hline
\end{tabular}

\section{Metode Penelitian}

Metode penelitian yang digunakan dalam pembuatan e-book menggunakan aplikasi sigil ver.0.9.4 sebagai berikut:

\subsection{Rancangan Penelitian}

Penelitian ini merancang model pembuatan buku digital (Electronic Book) yang mampu memberikan inovasi untuk sistem informasi khususnya dalam lingkup STMIK Citra Mandiri Padangsidimpuan . Peneliti menggunakan metode studi literatur yaitu dengan mengumpukan referensi dari berbagai sumber dan metode pengumpulan data dengan mengambil data pustaka, membaca, mencatat, dan mengolah bahan penelitian untuk 
pembuatan buku digital berformat epub .Dengan tujuan khusus sebagai berikut: menganalisis cara pembuatan E-Book menggunakan fitur SIGIL yang akan diterapkan pada STMIK Citra Mandiri Padangsidimpuan untuk menambah ilmu pengetahuan Program Studi Sistem Informasi STMIK Citra Mandiri Padangsidimpuan.

\subsection{Jenis Penelitian}

Metode penelitian ini bersifat kualitatif yaitu jenis penelitian yang menghasilkan penemuan-penemuan yang tidak dapat diperoleh dengan menggunakan prosedur-prosedur statistik atau cara-cara lain dari kuantifikasi (pengukuran) (Strauss dan Corbin).

\subsection{Studi Literatur}

Penelitian dengan studi literatur merupakan penelitian yang persiapannya sama dengan penelitian lainnya akan tetapi sumber dan metode pengumpulan data dengan mengambil data di pustaka, membaca, mencatat, dan mengolah bahan penelitian. Meskipun merupakan sebuah penelitian, penelitian dengan studi literatur tidak harus turun ke lapangan dan bertemu dengan menggunakan metode wawancara. Data-data yang dibutuhkan dalam penelitian dapat diperoleh dari sumber pustaka atau dokumen. Pada riset pustaka (library research), penelusuran pustaka tidak hanya untuk langkah awal menyiapkan kerangka penelitian (research design) akan tetapi sekaligus memanfaatkan sumber-sumber perpustakaan untuk memperoleh data penelitian (Zed, 2014).

\subsection{Analis dan Perancangan}

Dalam pemilihan metode penelitian ini penulis mempunyai alasan untuk memilih aplikasi sigil dan epub sebagai format buku digital adalah sebagai berikut:

- Format epub dapat menyesuaikan ukuran layar berbagai perangkat seperti smarthphone, tablet, laptop ataupun komputer.

- Aplikasi sigil bersifat opensource yang artinya memiliki fitur fitur yang gratis

- Format epub mendukung fitur audio dan video

- Aplikasi sigil bersifat multiplatform yang artinya dapat dijalankan di sistem operasi windows, linux dan Mac OS.

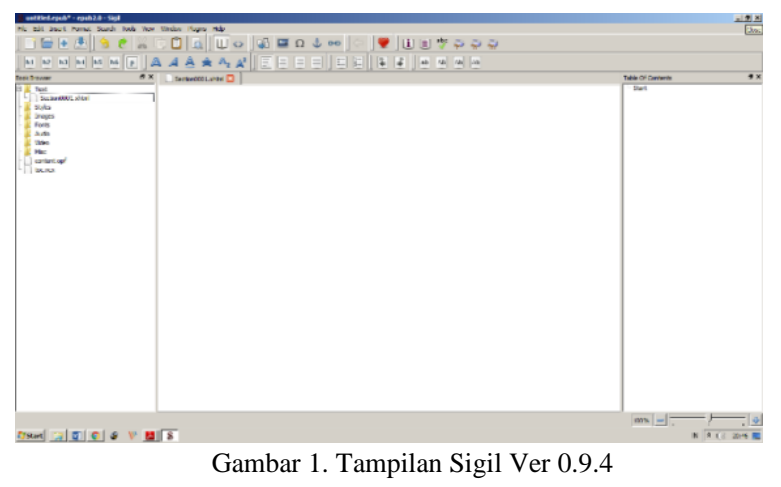

Tampilan sigil ver 0.9.4 pada gambar di atas terdapat tiga panel panel kanan, tengah dan atas. Panel kanan book browser berguna untuk menampung beberapa file pada epub seperti text, images, font, audio video dan lainnya. Panel tengah section pada sigil ver 0.9.4 berguna untuk menampilkan e-book yang akan kita edit ke format epub. Panel kanan Tabel of content berguna untuk daftar isi pada dokumen yang sedang kita buat ke format epub.

Untuk membuat e-book ke format epub kita harus menyediakan file/dokumen yang berisi materi yang telah siap kita kerjakan di Ms word dengan format doc ataupun docx yang nantinya akan kita konfersi ke format Web Page dengan cara pada save as pada Ms Word lalu pilih Web page, Filtered

\begin{tabular}{|l|}
\hline sejarah word 2007 \\
\hline Word Document \\
\hline Word Document \\
Word Macro-Enabled Document \\
Word 97-2003 Document \\
Word Template \\
Word Maco Enabled Template \\
Word 97-2003 Template \\
PDF \\
XPS Document \\
Single File Web Page \\
Wobpages- \\
\hline Web Page, Filtered \\
\hline Rich Text Format \\
Plain Text \\
Word XML Document \\
Word 2003XML Document \\
Stict Open XML Document \\
OpenDocument Text \\
\hline
\end{tabular}

Gambar 2. Konversi format doc/docx ke format web

Setelah kita buat ke format Webpage selanjutnya kita buka dokumen yang kita simpan tadi caranya klik file $\rightarrow$ add $\rightarrow$ Exsisting Files, sehingga hasilnya seperti ini : 


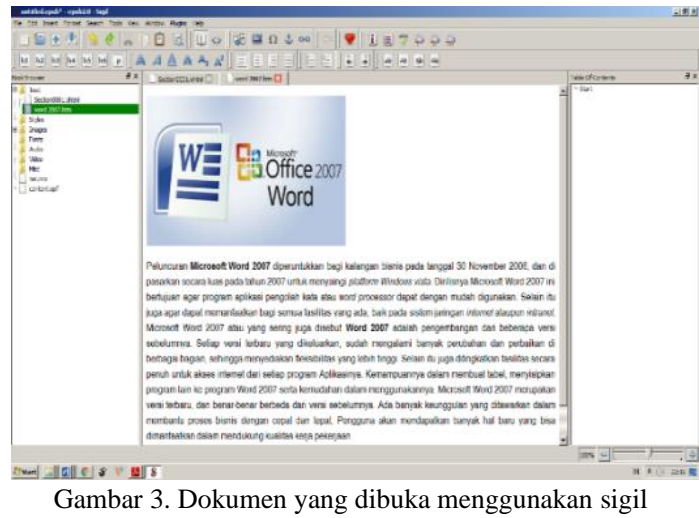

Setelah dokumen kita buka menggunakan aplikasi sigil kita bisa edit dengan menggunakan edit menggunakan fitur pada sigil seperti menambahkan link, manambahkan audio, video dan lain sebagainya, dalam penelitian ini saya akan memasukan file video ke dalam dokumen yang kita buat tadi pada aplikasi sigil, ikut langkahnya berikut ini :

- Pilih icon insert file

- Pilih Video

- $\quad$ Pilih Other Files

- $\quad$ Pilih video yang akan kita masukkan, disini saya masukkan video dengan nama word 2007

- lalu klik open

untuk lebih jelasnya perhatikan pada gambar Gambar 4 :

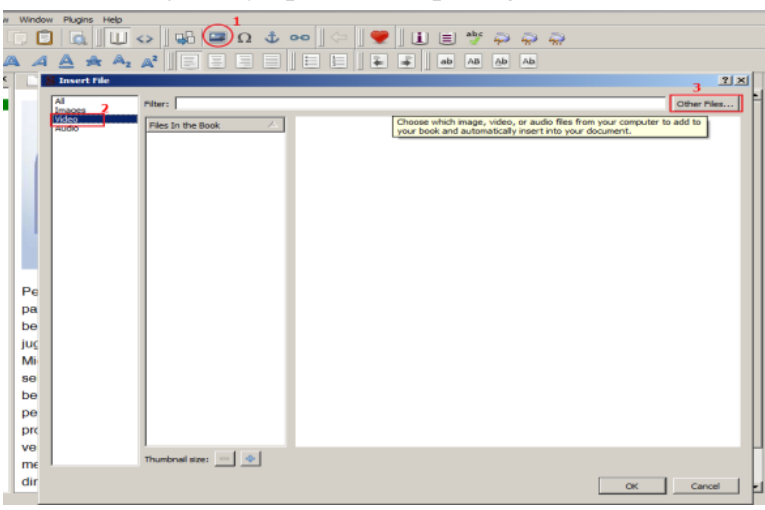

Gambar 4. Langkah 1 sampai 3

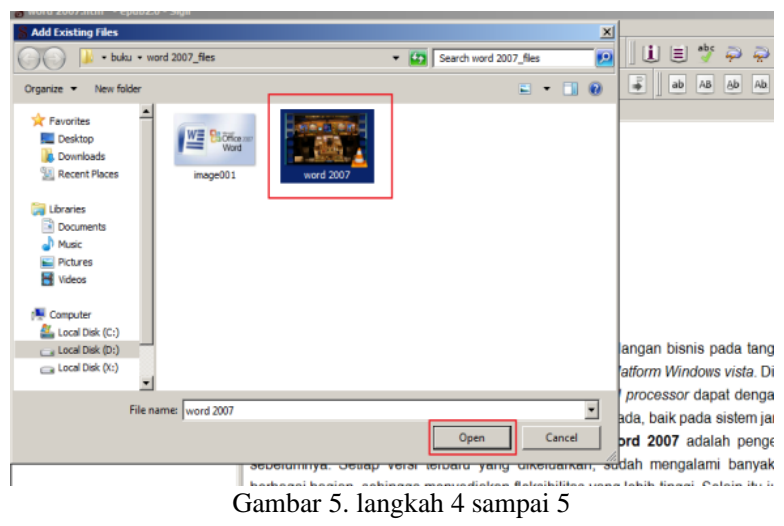

Maka hasilnya sebagai berikut :

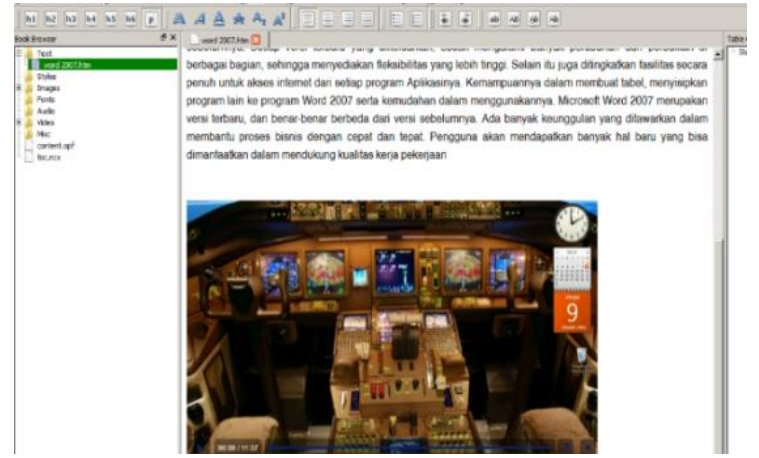

Gambar 6.Hasil memasukkan video kedalam dokumen aplikasi sigil

Selanjutnya kita akan membahas tentang MetaData Editor pada aplikasi sigil, fitur ini berguna untuk menambahkan Nama penulis, ISSN, ISBN, Tanggal pembuatan dokumen, Nama Penerbit dan lain sebagainya. Pada penelitian ini saya akan menambahkan nama penulis menggunakan MetaData Editor caranya klik Tools $\rightarrow$ MetaData Editor atau bisa menggunakan shortcut dengan menakan F8 pada keyboard

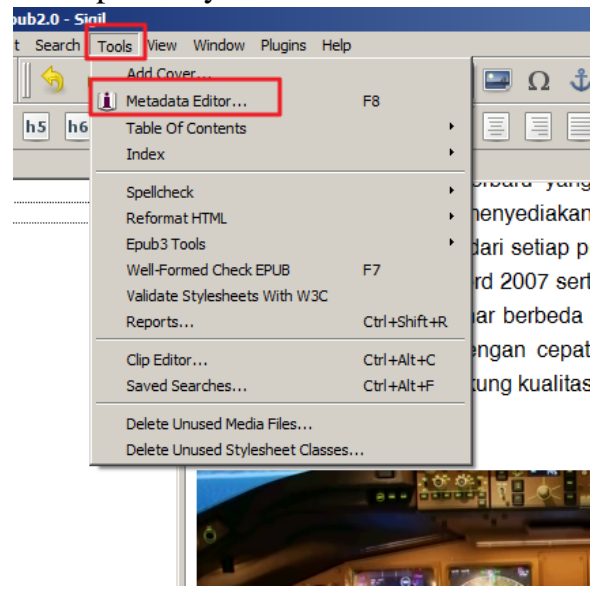

Gambar 7.Tools MetaData Editor

Setelah kita klik MetaData Editor maka akan muncul pop up Metadata Editor, pilih Add Metadata $\rightarrow$ pilih Author sebagai penulis , untuk lebih jelasnya perhatikan Gambar 8

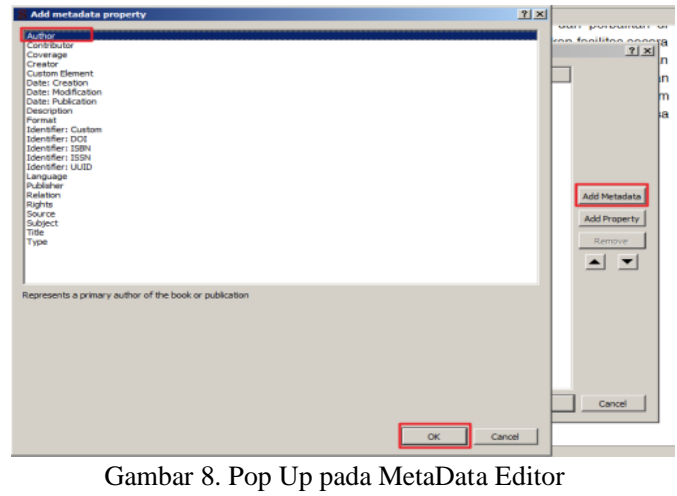

Setelah itu edit Author dengan cara klik dua kali pada 
dc:creator ubah nama penulis disini saya ubah Author dengan nama saya Ahmad Indra harahap lalu tekan ok

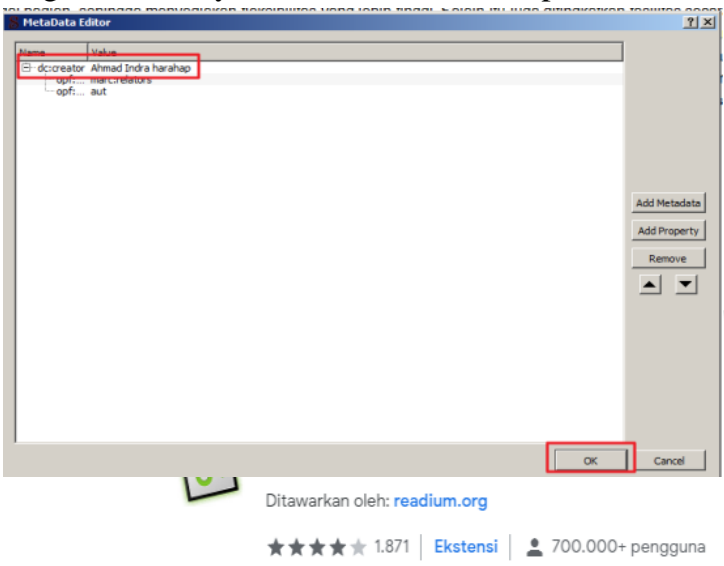

Gambar 9. Menambahkan nama penulis pada Sigil

Setelah kita menambahkan materi, video, nama penulis selanjutnya kita akan menambah cover/sampul pada ebook caranya yaitu klik menu Tools $\rightarrow$ Add Cover :

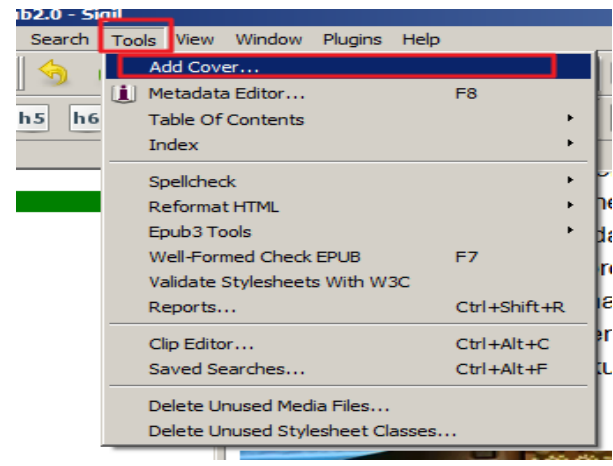

Gambar 10. Menambahkan Cover pada e-book lalu pilih Others Files cari cover untuk e-book . Ketika sudah ditambahkan maka hasilnya tampilannya terdapat pada Gambar 11

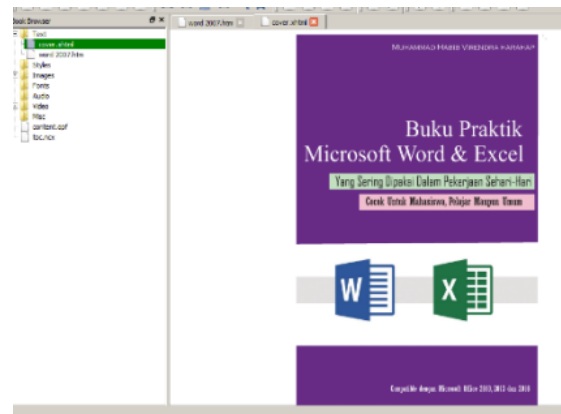

Gambar 11. Tampilan Cover e-book epub pada aplikasi sigil

Selanjutnya simpan dokumen yang kita buat ke dalam format epub klik File $\rightarrow$ Save As buat nama file dan simpan.

\section{Hasil dan Pembahasan}

Setelah kita berhasil membuat e-book dengan format epub selanjutnya kita akan melihat hasil e-book yang kita buat. Untuk menampilkan e-book berformat epub kita memerlukan aplikasi untuk membaca sebuah e-book berformat epub, ada berbagai macam aplikasi untuk membuka e-book berformat epub diantaranya adalah sebagai adalah :

- Untuk Google Chrome pada Sistem operasi Windows desktop instal Readium kita bisa mendapatkannya di Chrome Web Store secara gratis

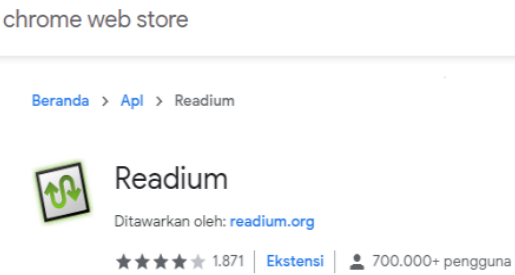

Gambar 12. Readium pada Google Chrome

- Untuk Smartphone Android instal Lithium kita bisa mendapatkannya di google Playstore secara gratis.

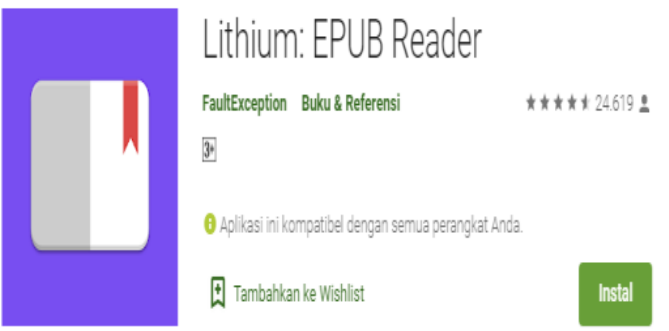

Gambar 13. Lithium pada Google Playstore

- Untuk Smartphone Iphone instal Apple Books kita bisa mencarinya di App Store Aple dan ini juga gratis.

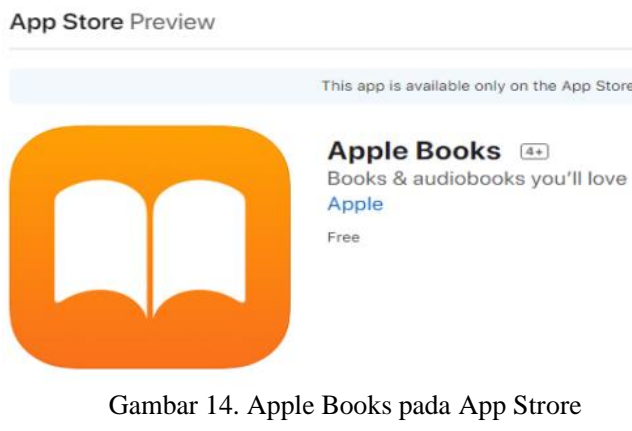

3.1. Hasil

Sekarang mari kita tampilkan hasil e-book yang kita buat sebelumnya dengan format epub 


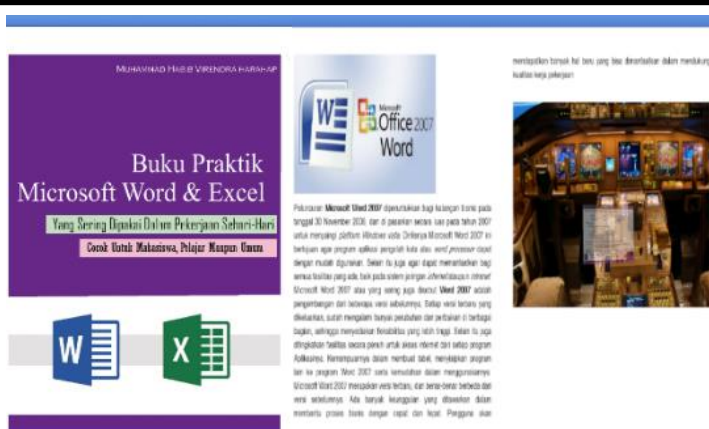

Gambar 15. Tampilan epub pada Readium Google Chrome

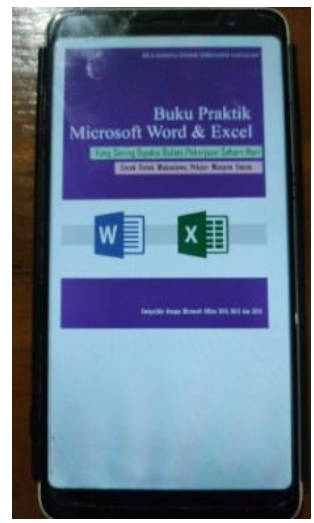

Gambar 16. Tampilan epub pada Smarthpone

\subsection{Pembahasan}

Dari Gambar 15. dan Gambar 16 dapat kita lihat bahwa buku digital berformat epub dengan menggunaka $n$ aplikasi dapat digunakan di berbagai perangkat dan berbagai sistem operasi dan untuk menggunakan aplikasi sigil sangatlah mudah dipelajari untuk membuat e-book atau buku digital bagi anda para pembaca.

\section{Kesimpulan}

Buku digital atau e-book dengan format epub mempunyai tampilan yang dinamis dibandingkan dengar format ebook lainnya ,karena dapat menyesuaikan ukuran dokumen di berbagai perangkat dan diberbagai sistem operasi seperti perangkat smartphone, laptop, Pc dan di berbagai sistem operasi seperti Windows, Linux , MacOs dan juga android.

Dalam aplikasi sigil Ver 0.9.4 untuk membuat e-book berformat epub mempunyai banyak fitur yang tidak ada di e-book lainnya seperti menambahkan audio dan video menambahkan author atau penulis, tanggal, nama penerbit dan juga banyak fitur - fitur lainnya. Dalam penelitian ini saya sebagai penulis dapat membuat e-book berformat epub dengan menggunakan aplikasi sigil ver 0.9.4 dengan mudah, ada berbagai macam tutorial dalam pembuatan epub menggunakan aplikasi sigil ini, bagi pemabaca dapat mempelajarinya juga di dalam penelitian saya ini. Sekian dan terimakasih bagi pembaca mohon maaf bila penelitian ini mungkin masih ada yang kurang bagi pembaca kedepannya insyaallah penulis akan membuat penelitian dalam pengembangan aplikasi sigil ini.

\section{Ucapan Terimakasih}

Ucapan terimkasih saya ucapkan kepada Allah SWT yang telah memberikan saya kesehatan rohani dan jasmani sehingga saya masih bisa menulis penelitian ini. Terimakasih kepada orangtua saya yang telah banyak membantu materi saya sehingga saya bisa seperti sekarang ini, dan ucapan terimakasih kepada Yayasan STMIK Citra Mandiri Padangsidimpuan yang telah membantu secara materi untuk mendanai dalam penelitian ini.

\section{Daftar Rujukan}

[1] Gardiner, Eileen and Ronald G. Musto. (2010). The Electronik Book. In Suarez, Michael Felix, and H. R. Woudhuysen. The Oxford Companion to the book: Oxford University Press, 2010, hlm. 164.

[2] Hameed, N., Cheah, Y. N., \& Rafie, M. (2010). An ebook personalization architecture with digital rights and encryption procedures. Information Technology ITSim 2010 International Symposium in.

[3] Marinai, S., Marino, E., \& Soda, G. (2011). Conversion of PDF Books in ePub Format. 2011 International Conference on Document Analysis and Recognition. IEEE.

[4] Kennedy, D. (2011). EPUB 3 : the Digital Publishing Standard is Revised and Expanded. Seybold Report, 11(16), 2-6.

[5] [2013]. Materi Simulasi Digital, hlm. 133-160.

[6] Nurmayanti , (2017) Pengembangan e-book interaktif berbasis representasi kimia pada materi ikatan kimia

[7] Restiyowati, I. \& Sanjaya, I.G. 2012. Pengembangan Ebook Interaktif Pada Materi Kimia Semester Genap Kelas XI SMA. Jurnal of Chemical Education. 1 (1): 130-135.

[8] Binas, M., Stancel, P. \& Michalko, M. 2012. Interactive EBook as a Supporting Tool for Education Process. International Conference on Emerging e-Learning Technologies and Applications, Departement of Computers and Informatics, Slovakia, November, 8-9th.

[9] Pratama, D.A. \& Rakhmawati, L. 2013. Pengembangan Media Pembelajaran E-Book Interaktif pada Mata Pelajaran Elektronika Digital di Jurusan Teknik Elektro Unesa. Jurnal Pendidikan Teknik Elektro. 2 (1): 327-332.

[10] Rosida, Fadiawati, N. \& Jalmo, T. 2017. Efektivitas Penggunaan Bahan Ajar E-Book Interaktif dalam Menumbuhkan Keterampilan Berfikir Kritis Siswa. Jurnal Pembelajaran Fisika. 5 (1): 35-45.

[11] Amalia, F, dan R Kustijono, "Efektifitas Penggunaan EBook Dengan Sigil Untuk Melatihkan Kemampuan Berfikir Kritis”, SEMINAR NASIONAL FISIKA (SNF) 
2017 "Menghilirkan Penelitian-penelitian Fisika Dan Pembeajarannya", 25 (2017), h.84.

[12] FiturAplikasiSigil" $<$ https://mustahfhidz.wprdpress.com /2017/05/17/fituraplikasi-sigil> [accessed 10 September 2020].

[13] Hidayat, Rahmat, Erwandi, Vitrianratna Sari, dan Vide Rawi Purnama Ade,"Pemanfaatan Sigil Untuk
Pembuatan E-Book (Electronic Book) Dengan Format Epub”, TEKNOSI, 03 (2017)

[14] Tristyo Krishartomo, S.Kom. Dikembangkan oleh J,Haritz CN, (2013). PANDUAN PEMBUATAN BUKU DIGITAL INTERAKTIF DENGAN MENGGUNAKAN SIGIL

[15] Elyas, S.Pd, M.Eng \& heri Yudianto, S.T . Mudahnya buat buku digital bersama SIGIL . (2016). 